Acta Poetica 25-1

PRIMAVERA

2004

\title{
El traductor burlado en algunas versiones del Decamerón
}

\author{
María Cristina Azuela
}

En este trabajo se coteja el tratamiento de algunos recursos estilísticos en distintos relatos del Decamerón que dan cuatro traducciones al español y una al francés. Esta comparación revela cómo, en muchas ocasiones, las intenciones de Boccaccio son pasadas por alto por los autores de estas versiones.

This article compares five different translations of the Decameron (four in Spanish and one in French). Based on the treatment of different stylistic devices throughout the text, we can conclude that these versions seem to have neglected the author's intentions. 


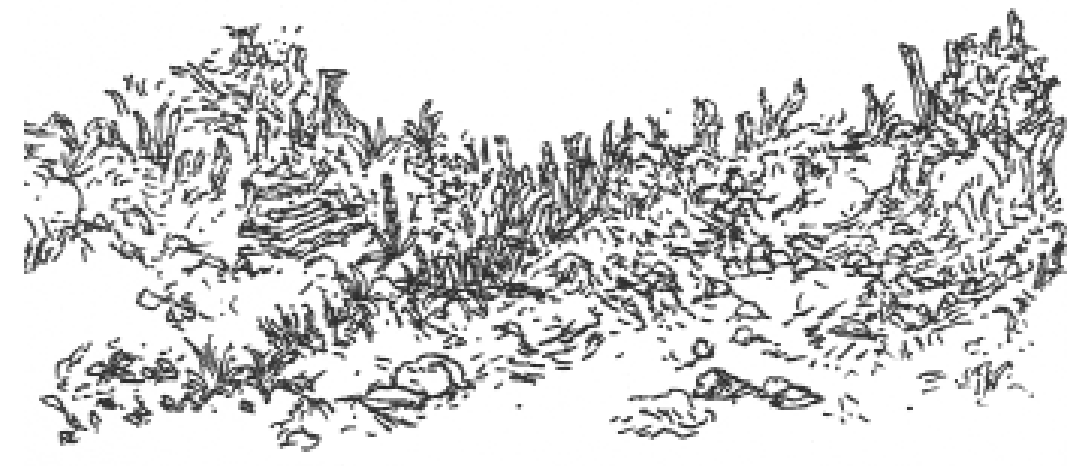


Acta Poetica 25-1

PRIMAVERA

2004

María Cristina Azuela

\section{El traductor burlado en algunas versiones del Decamerón}

Todos los que hemos impartido clases nos hemos enfrentado una u otra vez a la mirada en blanco de algún alumno. Pero me ha resultado especialmente sorprendente cuando ésta no se debe a la incomprensión o ignorancia del estudiante, sino a su estupor. Estupor y desconcierto ante alusiones mías a alguna obra de otra lengua que la clase leyó en traducción, y que me ha revelado que el texto que yo comento no es el mismo que ellos estudiaron, debido a la falta de esmero de la versión que leyeron. Esto ha resultado evidente sobre todo cuando, al referirme a algún juego de palabras o efecto verbal cómico del Decamerón, me encuentro con reacciones de seriedad que para mi asombro no se deben a errores de lectura o negligencia por parte de los estudiantes ¡sino de los traductores! Al respecto, hace algunos años Mariapia Lamberti no podía evitar su extrañeza ante la variedad de ediciones de esa obra que, señalaba, "circulan libremente por las librerías del mundo hispánico" a pesar de las inusitadas libertades que los traductores se toman con el texto original, ${ }^{1}$ y cuyo menor daño son las expresiones de estupefacción de los alumnos cuando el profesor cita

\footnotetext{
${ }^{1}$ Lamberti, "Teoría literaria".
} 
líneas que aparecen totalmente transformadas —o deformadas-, si no es que ausentes, en sus versiones. En las páginas que siguen, presentaré algunos ejemplos que he ido encontrando en ciertas traducciones de la obra italiana, a lo largo de diversos cursos y lecturas personales. ${ }^{2}$ A partir de la edición, ya canónica, de Vittore Branca, cotejaré la excelente versión de María Hernández de la editorial Cátedra, con la de Jaime Schuartz de Editores Mexicanos Unidos, la de Luis Obiols de la Editorial CREDSA, la versión a cargo de Caridad Oriol de la editorial Bruguera, y por último, la traducción al francés de Jean Bourciez de Garnier Frères.

Como se sabe, en el Decamerón abundan las historias en que algún astuto se burla de otros más ingenuos cuya estupidez hace incluso que la broma parezca justificada. Y es notable que los ardides del tramposo se apoyen generalmente en discursos embusteros que embrollan al burlado en una red de mentiras difícil de desentrañar. En ocasiones, éstas parecen aderezadas por juegos de palabras donde se establecen dos niveles de comprensión, y donde la víctima entiende una cosa y su burlador otra muy distinta que comparte con el lector. Para ello, una de las armas más efectivas es el empleo de la ambigüedad, que algunos personajes aprovechan de manera brillante. Es el caso de las afirmaciones engañosas del hermano Cipolla (VI-10), quien, narrando su recorrido por una serie de lugares lejanos de costumbres portentosas, menciona unas tierras donde:

... l'anno di state vi vale il pan freddo quatro denari e il caldo v’è per niente (VI-10, $\S 43)$.

\footnotetext{
2 Justamente este trabajo fue cobrando forma a raíz de la elaboración de varios artículos sobre el empleo del lenguaje en la nouvelle medieval (Azuela, "Los cálculos"; "Razonamientos sofísticos"; y más recientemente "Juegos"). Varios ejemplos ahí examinados fueron el punto de partida para cotejar diferentes versiones al español y comprobar la indiferencia de algunos traductores ante los recursos estilísticos de Boccaccio.
} 
Literalmente se trata de lugares donde "durante el verano el pan frío os cuesta cuatro dinares, y el caliente os lo dan gratis", ${ }^{3}$ pero si se toma en cuenta que en el italiano hay un equívoco que parte de la polisemia del término "caldo" — que significa tanto "caliente" como «calor»-, queda claro que el bromista parte de la alusión al «pan frío», para luego, con la palabra "caldo" referirse "al clima caliente" que, efectivamente, suele ser gratuito, pero enredando a sus oyentes, quienes presumiblemente pensarían que también el "pan caliente" era regalado. Para respetar la ambigüedad y conservar el efecto cómico, la frase podría ser traducida como:

... un país donde durante el invierno el pan caliente os cuesta cuatro dinares, y el frío es gratis (mi traducción).

(aunque fuera necesaria una nota que explicara la transformación del contenido).

Entre las versiones cotejadas, solamente Bourciez pudo respetar la ambigüedad pues al igual que "caldo", "chaud" puede ser tanto adjetivo como sustantivo:

... où durant la saison d'été le pain rassis coûte quatre deniers, et le chaud rien du tout (Bourciez, 430).

María Hernández Esteban pone una nota que señala el juego de palabras, pero prefiere traducir literalmente (739), sin embargo, el resto de los traductores, simplemente ignoran el equívoco sin que sea posible saber si pasaron por alto las intenciones cómicas del autor, o si simplemente les pareció complicado intentar reproducir la ambigüedad. ${ }^{4}$

\footnotetext{
3 Todas mis traducciones intentan conservar hasta donde es posible los rasgos estilísticos y los juegos de palabras del original, y han sido cotejadas con las de la cuidadosa edición de María Hernández Esteban, de la editorial Cátedra, que suele presentar soluciones brillantes a los problemas de traducción. Sin embargo, para resaltar ciertos detalles he preferido alguna modificación que esa versión no contempló.

${ }^{4}$ Luis Obiols, 513: "donde en el verano el pan frío os cuesta cuatro dineros y
} 
Se podría inventariar una gran variedad de trucos verbales como el anterior, que sirven a algunos bromistas para apabullar el de por sí no muy esclarecido entendimiento de sus víctimas. Lo que resulta sorprendente es que en muchos casos los traductores se identifiquen con estos últimos en vez de compartir la broma con el autor.

En otro lugar he sugerido que para despistar a aquellos a quienes quiere perjudicar, el tramposo suele transgredir las reglas más elementales de la comunicación tal como las han propuesto los teóricos de los actos de habla, pero que la genialidad de Boccaccio no radica solamente en la falta de veracidad o de "pertinencia" del que engaña, sino también en el exceso de "cooperatividad" del burlado que a veces presta sentido a frases que expresamente carecían de él. Es el caso del relato VIII-3, donde Calandrino llega a creer que una piedra (el «heliotropo») $)^{5}$ tiene el poder mágico de otorgar la invisibilidad, a partir de una afirmación equívoca de Maso del Saggio, quien expresa, como si fuera una cosa maravillosa, que se trata de:

... una pietra, la quale noi altri lapidarii appelliamo elitropia, pietra di troppo gran vertù, per ciò che qualunque persona la porta sopra di sé, mentre la tiene, non è da alcuna altra persona veduto dove non è (VIII-3, §20).

[... una piedra a la que nosotros los lapidarios llamamos heliotropo, piedra de muy gran poder, porque a cualquiera que la lleve encima, mientras la tenga, nadie le verá donde no está (Hernández Esteban, 866)].

el caliente os lo regalan"; Schuartz, 343: "donde durante el verano el pan frío cuesta cuatro dineros y el caliente os lo dan de balde". La versión de la Editorial Bruguera suprime estas frases, como suele hacerlo constantemente (279).

${ }^{5}$ María Hernández Esteban señala que "en mineralogía el heliotropo es el jaspe verde oscuro con manchas rojas muy apreciado para hacer vasos y jarrones" (en su nota de la p. 866 del Decamerón). 
Por el afán con el que Calandrino se apresura a hacerse con la famosa piedra, es obvio que, a pesar de que literalmente Maso le había asegurado que cada vez que la llevara consigo sólo sería invisible donde no estuviera, el crédulo, en tanto que interlocutor "cooperativo", estuvo dispuesto a corregir lo que supuso fue un error involuntario del pícaro, para otorgar sentido a su frase. Como en el caso de los fieles de Certaldo, a quienes Cipolla (VI-10) ${ }^{6}$ había engañado con una frase similiar, Calandrino ha caído en una trampa linguiística muy elaborada que se inició con una larga descripción bastante fantasiosa del país de origen de la piedra. Todo lo relacionado con esa región parecía fabuloso (nombres, situación geográfica, características del lugar), ${ }^{7}$ por lo que se hacía probable que las piedras que se encontraran ahí también lo fueran. Así pues, cuando Maso pronunció su frase engañosa, resultaba obvio que Calandrino le prestaría un sentido de acuerdo con el resto de los hechos milagrosos que había escuchado. ${ }^{8}$

\footnotetext{
${ }^{6}$ Para obtener limosnas de sus parroquianos, Cipolla los confunde con una avalancha de datos incluidos en un discurso pletórico de maravillas y reliquias asombrosas, adrezado con frases ambiguas como la que mencionamos arriba, y que culmina con la exhibición de los supuestos carbones que sirvieron para asar a San Lorenzo. El fraile propone que a cambio de sus donativos: "chiunque da questi carboni in segno di croce è tocco, tutto quello anno può viver sicuro che fuoco nol cocerà che non si senta" (VI-10, §52) [«quienquiera que lleve la señal de la cruz de estos carbones, durante todo este año podrá vivir con la seguridad de que el fuego no lo quemará sin que lo sienta» (mi traducción)].

${ }^{7}$ Basta ver el párrafo 9 de la historia, como lo señalo en "Los cálculos". Para todo lo que respecta a este relato he retomado este artículo.

${ }^{8}$ En otro lugar he señalado que el deseo de Calandrino de dar crédito a las maravillas que le contaba Maso no será sobrepasado más que por el del maestro Simón frente a las historias de Bruno y Buffalmacco en el relato VIII-9, que aquí comentaremos. Maese Simón no será simplemente una víctima «cooperativa» como lo fue Calandrino, sino que incluso parece exigir de sus burladores la invención de una historia fuera de lo común: intrigado por la notoria alegría de los dos amigos, Simón busca la causa de su felicidad, ya que siendo tan pobres, no había ninguna razón para tanta dicha, y les pide que compartan su secreto con él. Ante la necedad de la petición Bruno decide engañarlo. Retomando los procedimientos retóricos de Cipolla, ambos pícaros aprovechan la sonoridad exótica de términos geográficos inventados; fabrican listas interminables de títulos nobiliarios y burlescos de damas inexistentes; le asestan a su víctima insultos enmas-
} 
No es descabellado imaginar que Boccaccio contaba con lectores avisados que apreciarían el especial cinismo del bromista y compartirían la broma con él. Sin embargo, no todos resultan ser tan atentos y es curioso que algunos traductores hayan caído en la trampa de Maso, y no duden en corregir su frase. Jaime Schuartz, la deja como:

...una piedra que nosotros los lapidarios llamamos elitropía, piedra de virtud demasiado extraordinaria, pues todo el que la lleva encima, no es visto por nadie donde está (Schuartz, 401).

con lo que sustrae todo el sentido a la burla perpetrada por el protagonista, aunque le queda clara la intención de hacer parecer como fuera de lo común a la piedra — por lo que añade lo de "demasiado extraordinaria".

Pero no es el único en caer; la traducción de la editorial Bruguera, que suele transformar con demasiada libertad el texto original, presumiblemente para acortarlo, no sólo desmantela la broma mientras resume un largo párrafo, sino que deja una redacción poco elegante:

La otra piedra, que los lapidarios llaman helitropía, quien la llevara encima tendría la propiedad de ser invisible (Bruguera, 329).

Como se ve, resulta interesante que los traductores hayan terminado por enredarse, justo como el bromista esperaba que le sucediera a su víctima. Hay, sin embargo, otras variantes: Luis Obiols parece haber entendido el chiste, pero es incapaz de re-

carados bajo frases de apariencia halagadora; lo apabullan con términos incomprensibles y enunciados de sintaxis equívoca donde nuevamente es la "cooperatividad" del oyente lo que dota de sentido extraordinario a las banalidades más evidentes, si no es que a las alusiones escatológicas más vulgares (v. "Los cálculos", 105). 
producirlo sin introducir la palabra "invisible", con lo que podría pensarse que el propio Maso hace un razonamiento erróneo, lo cual no podría estar más alejado de la mofa original:

piedra [...] que nosotros, los lapidarios, llamamos heliotropo, de virtud extraordinaria, pues el que la lleva consigo se hace invisible, de manera que ningún otro hombre puede verlo donde no está (Obiols, 606).

En el caso de Calandrino, es plausible que su interpretación errónea de la frase se debiera a la especie de reacción automática que suelen tener los interlocutores de buena fe durante los intercambios verbales, que lo habría llevado a corregir un supuesto "error" de su amigo. Sería lógico, incluso, que no sólo se tratara de un simple afán de corrección, sino de un comprensible anhelo de participar - y sacar provecho- de la magia de la famosa piedra. En cambio, el caso de los traductores es un poco más difícil de explicar, pero resulta evidente que al demostrar su inesperada "cooperatividad" se identificaron plena, aunque involuntariamente, con el personaje burlado. ${ }^{9} \mathrm{Y}$ no es la única ocasión en que les sucede. En el Decamerón aparece otra situación similar donde, a través de una frase muy parecida, Bruno y Buffalmaco embroman al Maestro Simón y, al corregirla equivocadamente, de nueva cuenta los traductores desencaminan las intenciones del autor. En este caso, se trata de la mención de las variadas damas de alta alcurnia que los burladores quieren hacer creer, no sólo que alternan con ellos, sino que gracias a las cuales:

quando noi vogliamo un mille o un dumilia fiorini da loro noi non gli abbiamo (VIII-9, §28)].

\footnotetext{
9 Sorprende aquí la inadvertencia de los traductores que, en general, habían comprendido perfectamente la burla de la frase de Cipolla arriba citada (nota 6), y sin embargo pasaron por alto ésta y las que siguen.
} 
[cuando queremos de ellas un millar o dos millares de florines, no los obtenemos (mi traducción)].

Jaime Schuartz parece traducir literalmente el verbo avere ["tener"], con la salvedad de que corrige el sentido de la frase, enmendando lo que suponía era un error, con lo que demuestra que el procedimiento del personaje burlador de "sembrar expectativas positivas" (como lo expresa María Hernández Esteban),${ }^{10}$ da resultados excelentes:

cuando queremos un millar o dos millares de florines, los tenemos (Schuartz, 438).

Otro ejemplo de ello, lo proporciona Luis Obiols, quien no sólo enmienda, sino que completa, arbitrariamente, pero en el sentido que supone correcto, como para dar más fuerza a la frase:

cuando queremos mil o dos mil florines, les tenemos al instante (Obiols, 662).

Hay que subrayar que de manera similar al ejemplo anterior - y siguiendo el procedimiento de Cipolla (v. nota 6) - , justamente este pasaje había sido preparado por una divertida enumeración de reinas y emperatrices imaginarias, cuyos títulos fantasiosos y burlescos tenían por objeto la desorientación del oyente. Bruno había enlistado a:

la donna de' barbanicchi, la reina de' baschi, la moglie del soldano, la 'mperadrice d'Osbech, la cianciafera di Norrueca, la semistante di Berlinzone e la scalpedera di Narsia [...] infino alla schinchimurra del Presto Giovanni... (VIII-9, § 23).

${ }^{10}$ Obviamente esta traductora sí respeta lo engañoso de la frase, y comenta en una nota detallada ese procedimiento de "sembrar expectativas positivas" (v. Decamerón, nota 23, 937). 
[La reina de los barbaniches, la reina de los vascos, la esposa del sultán, la emperatriz de Osbech, la engañatriz de Norrueca, la semistante de Berlinzoni y la pelandrera de Narsia [...] hasta la chinchimurra del Preste Juan... ${ }^{11}$ (mi traducción)].

En su versión, Schuartz se limitó a suprimir el catálogo de las damas inexistentes, coincidiendo con el traductor al francés, Jean Bourciez, quien redujo la variedad de títulos a uno único, el de "princesa". Si a Schuartz le había parecido complicada o incomprensible la lista de nombres estrambóticos, su reacción resultó ser exactamente la que tenía prevista el pícaro que los produjo, quien contaba con que, ofuscado por la avalancha de vocablos incomprensibles, el Maestro Simón cayera sin sospecha en la trampa arriba citada de los florines, justo como Schuartz ${ }^{12}$ cayó en ella y transformó la frase negativa en afirmativa. ${ }^{13}$ Sin embargo, la respuesta más curiosa no es la de Schuartz o la de Bourciez, que suprimieron los títulos “enigmá-

\footnotetext{
${ }^{11}$ Los términos "cianciafera", "semistante", "scalpedra", y "schinchimurra" son títulos inventados cuya sonoridad exótica remite a países lejanos y costumbres tan extrañas como los nombres mismos, aunque además incluyen dobles sentidos (como "cianciafera", que tiene ecos de "ciancia" [embuste, parloteo, chismorreo] o "scalpedra" que, siguiendo a María Hernández, suena a "pelandusca", por lo que ella la traduce como "pelandrera"). Por otro lado, "Norrueca" es una deformación de Noruega; "Berlinzone" y "terra dei Baschi" [tierra de los vascos] representan países lejanos y fabulosos (para todos estos términos, v. la nota de Branca a este relato (nota 43, 1123) y la de María Hernández Esteban, donde afirma que se trata de nombres exóticos "formados la mayor parte con la fusión de raíces semánticas dispares y casi siempre equívocas" (Decamerón, nota 20, 936).

12 Y no sólo él, como lo veremos ( $c f$. también la versión de la editorial Bruguera, más cercana a la traducción de Bourciez, pero que igualmente elimina los títulos extraños, y por supuesto, termina por caer en el mismo error de los florines [Bruguera, 356-357]).

${ }^{13}$ Bourciez transforma la frase en una interrogación sin respuesta, que queda como una afirmación ambigua, con lo que sin alejarse totalmente del original soslaya la intención directa de embromar al interlocutor afirmando algo que obviamente éste va a interpretar como lo contrario de la significación literal: "si nous leur demandons un millier ou deux de florins, est-ce que nous les touchons, ou non?" (Le Décaméron, 559).
} 
ticos", sino la de Luis Obiols, quien, tal vez justo por haber respetado la lista y haberse debatido ante la dificultad de traducir los títulos exóticos, termina por empantanarse en el asunto de los florines y pone la frase en afirmativo, como lo citamos arriba.

Este ejemplo de los títulos fantasiosos es particularmente significativo porque unas líneas más tarde se entablará una discusión burlesca con respecto a ellos, cuando Bruno mencione a otra de sus conocidas: "la gumedra del gran can d'Altarisi" (VIII-9, §35) ["la jumendra del Gran Khan de Altarisi'], ${ }^{14}$ y el maestro Simón pregunte:

- Che vuol dir gumedra? Io non gl'intendo questi nomi.

- O maestro mio - diceva Bruno- io non me ne maraviglio, ché io ho bene udito dire che Porcograsso e Vannaccena non ne dicon nulla.

Disse il maestro : - Tu voui dire Ipocrasso e Avicena.

Disse Bruno : - Gnaffé ! io non so : io m'intendo così male de' vostri nomi come voi de' miei; ma la gumedra in quella lingua del gran cane vuol tanto dire quanto imperadrice nella nostra... (VIII-9, §36-39).

[-¿Qué quiere decir jumendra? Yo no los entiendo estos nombres.

- ¡Oh, maestro mío - decía Bruno- no me extraña, porque bien he oído decir que Puercócrates y Vanacena no dicen nada de ellos!

Dijo el maestro:

-Quieres decir Hipócrates y Avicena.

Dijo el Bruno:

- ¿Qué caray! No sé; entiendo tan mal vuestros nombres como vos los míos, pero la jumendra, en la lengua del Gran Kan, es como decir emperatriz en la nuestra... (Hernández Esteban, 938)].

14 Tomo la versión de María Hernández Esteban quien traduce "gumedra” por "jumendra” por su similaridad con "jumenta” (Decamerón, 938), aunque, como se verá, es un título inexistente. Por su parte, "Altarisi" podría acercarse a Altai, una región descrita por Marco Polo (v. supra, nota 11). 
El diálogo anterior muestra que el propio Boccaccio parecería hacer un guiño y volver explícito todo el juego de sus personajes alrededor de los términos inventados y de los malabarismos verbales con los sonidos de los títulos exóticos. Este solo hecho hace que resulte escandalosa la poca curiosidad que algunos traductores dedicaron al asunto, pues simplemente suprimieron también este párrafo. ${ }^{15}$ Luis Obiols, que se había tomado el trabajo con los títulos de las damas, también respeta el fragmento, como comprendiendo su relación entre ambas secciones; en cambio llama la atención que Bourciez se ocupe de traducirlo (560), a pesar de que antes había omitido los títulos de las damas, con lo que nuevamente se demuestra una falta de cuidado respecto del contenido del texto.

No es la única ocasión en que a través de la locuacidad e invención de vocablos el autor desenmascara el fraude verbal que sus personajes realizan. En la historia de Cipolla, donde como ya señalamos (v. nota 6), se hace un despliegue de artificios retóricos para engañar a los fieles, en algún momento el fraile menciona haber viajado por ciertos países llamados "Truffia" y "Buffia", e incluso por la "terra di Menzogna" (VI-10, §39). En este caso, los traductores tienden, en general, a trasladar sin modificar mayormente los nombres pues, tanto en italiano como en español "truffa" significa "fraude" y " buffo" es "cómico o gracioso", aunque en el original es inevitable la analogía con "beffa", "engaño", ${ }^{16}$ que se ligan perfectamente a la mención en la línea siguiente de la "terra di Menzogna" en casi todos los casos traducida como "país de la mentira". ${ }^{17}$

\footnotetext{
${ }^{15}$ V. tr. Schuartz, 439, y edit. Bruguera, 357, que omiten toda la discusión.

16 Justamente el tipo de relato que narra las trampas de un burlador hacia una víctima se denomina "beffa", por lo que este género está muy bien representado en el Decamerón.

${ }^{17}$ Mientras que Obiols deja "Truffia y Bufia" (512 ); la versión de la editorial Bruguera, transforma "Truffia" en "Traffia" con intenciones poco claras (279). Hay que reconocerle a Schuartz que traduce "Truffia y Ruffia", tal vez ésta última por la cercanía con "rufián", aunque inmediatamente después inventa "tierra de Nenzagna" (343). Bourciez traduce como "j'arrive en Truffe et en Bouffe"
} 
Así pues, a pesar de que no es improbable que todos ellos hayan respetado conscientemente la forma italiana que conserva en español el sentido de "mentira", realmente parece que no explotaron en toda su amplitud el juego del orador, quien, a través de estos nombres, hacía evidente su intención de burlarse explícitamente del auditorio. En una versión a la mexicana esto podría quedar claro si se tradujera como "Trampozotlán y Burlatepec”, aunque María Hernández Esteban lo intenta también al dejar "Estafia y Befia" (738).

Hay que aclarar, por otro lado, que, como hemos visto en los ejemplos mencionados, el autor italiano constantemente pone en boca de sus personajes lapsus o deformaciones de palabras y contrasentidos que tienen por objeto confundir a alguien. Pero existen otras ocasiones en que los barbarismos y la sintaxis embrollada de algún personaje forman parte, no sólo de su caracterización burlesca - lo cual ya es importante-, sino también de la justificación de la chanza que sufrirá.

Ya hemos mencionado a Calandrino, quien en repetidas ocasiones - y en diferentes relatos- es víctima de sus pícaros amigos (v. IX-3, VIII-6 y IX-5), y casualmente, en una de ellas, también se expresa mal, pues al enviar un mensaje de amor, dice al amigo que lo llevará:

Tu sì le dirai $[\ldots]$ che io son suo servigiale (IX-5 § 27)

[tu le dirás que soy su servicial (por su servidor)].

El error en que incurre el personaje trata de traducir no sólo su nerviosismo ante la bella, sino, sobre todo, su ya conocida necedad. Sin embargo, todas las versiones aquí cotejadas - ex-

(429), con lo que traslada la isotopía del engaño a la de la glotonería pues "truffe" es "trufa" - "truffer"="rellenar"-, y "bouffe" es "comida" en registro familiar, aunque también se conserva el sentido de "gracioso" derivado del italiano, como en la "ópera bufa". 
cepto, por supuesto la de María Hernández Esteban- parecen no haberse percatado de la intención del autor, y se esmeran en corregir el vocablo deformado del personaje, por una frase perfectamente coherente: "... que estoy a su servicio" ( $c f$. Schuartz, 468; Bruguera, 386; Obiols, 714; Bourciez, 602).

Aunque de hecho parece un detalle sin importancia, hay otras ocasiones donde el narrador caracteriza la estulticia de algún personaje a través de sus palabras incorrectas y donde se vuelve a advertir la intervención errónea del traductor. En los relatos II-8 y VIII-2 el marido cornudo se expresa con una visible falta de control sobre su propio lenguaje, lo que de alguna manera excusa la infidelidad de su esposa (hay, en las historias de adulterio, muchas otras razones: celos injustificados, estatus social más bajo, o incluso un origen no florentino de los maridos).

En III-8, el marido engañado cree haber pasado un tiempo en el Purgatorio y al narrar cómo habló con el arcángel Gabriel, pronuncia «el arañel Grabiel» (en italiano: «Ragnolo Braghiello» (III-8, §74), en vez de Agnolo Gabriello). Las connotaciones burlescas del lapsus, más cómico aún por ser involuntario, se fundan en los ecos del término "brache" [bragas, calzones] en "Brahiello", y de "ragno" ["araña"], en Ragnolo, y no deberían pasar inadvertidas. ${ }^{18}$ Sin embargo, no todos los traductores las captan: tanto Jaime Schuartz (195) como Luis Obiols (289), ignoraron la burla que el narrador hace al personaje y corrigieron su "equivocación". 19

\footnotetext{
18 Estas connotaciones son muy difíciles de reproducir en la traducción, y aunque me baso en la versión de María Hernández Esteban, he incluido una metátesis típica del habla popular transformando "Gabriel" en "Grabiel". María Hernández Esteban traduce como "Arañel San Braguiel" y conserva la relación con "bragas", que para el lector español es más inmediata (v. Decamerón, 452).

${ }^{19}$ La versión de la editorial Bruguera, que como ya se dijo, omite párrafos enteros, tampoco incluye éste (164). Bourciez deja "ange "Garbiel", perdiendo también las resonancias con "brache” y con "ragno” (242).
} 
La anterior permutación "accidental" de fonemas recuerda los idiotismos y corrupciones de palabras de Bentivegna del Masso - otro marido engañado, en VIII-2-, cuyas confusiones y redundancias producen un discurso especialmente cómico:

...io vo infino a città per alcuna mia vicenda [por facenda]: e porto queste cose a ser Bonaccorri da Ginestreto, che m'aiuti di non so ché m'ha fatto richiediere per una comparigione del parentorio [por perentorio] per lo pericolator [por procuratore] suo il giudice del dificio [por giudice del maleficio] (VIII-2, par. §14).

Se trata no solamente de una deformación burlesca de los vocablos, sino también de un enredo de la sintaxis, cuya traducción podría ser:

[Voy hasta la suidá [por ciudad] por algún encargo: y le llevo todo esto al señor Bonaccorri da Ginestreto, pa' que mi ayude porque disque soy querido [por requerido] por el puercurador [por procurador] para una comparación del perentorio [por comparecencia perentoria] del juez de lo creminal].

Branca ha señalado lo que el personaje probablemente quiso decir:

[voy hasta la ciudad a llevarle esto al señor Bonaccorri da Ginestreto, para que me ayude pues] ${ }^{20}$ "el juez de lo criminal me ha citado por medio de su procurador para una comparecencia perentoria".

Es curioso que los traductores nuevamente ignoren las intenciones de parodiar la estupidez del personaje e intenten enmendar la incoherencia de la parrafada. A veces resumida y en

${ }^{20}$ Branca solamente traduce el final de la frase en su nota 32, 1099. 
discurso indirecto (Schuartz, 397), o respetando la forma pero corregida (Obiols, 599-600). Sólo Bourciez, aunque rectifica casi todo, parece darse cuenta del propósito del narrador, y deja al menos una palabra deformada "porcurateur" (Bourciez, 504); aunque el colmo lo da la versión de la editorial Bruguera, donde no solamente se ignora la burla y se expurgan los "errores", sino que se modifica el sentido de la frase, y donde Bentivegna llevaba regalos para obtener ayuda, aquí resulta que es Micer Bonnacorri quien "requiere mi ayuda sobre cosas de un pleito" (325)...

Otro caso es la deformación de "Hipócrates y Avicena", citada más arriba, cuyo objeto radicaba en hacer sentir superior al maestro Simón, quien podía incluso sentirse superior al corregir a Bruno, aunque al mismo tiempo, éste no dejaba de mofarse al aludir explícitamente al resto de las palabras inventadas que había pronunciado para engañarlo. Ya se ha mencionado que en dos de las versiones aquí examinadas este diálogo fue suprimido (v. nota 15), pero hay que reconocer que los otros dos traductores respetan las deformaciones originales. ${ }^{21}$

Como se ve, sean cuales fueren las causas de los continuos "lapsus" en el texto, resulta notable que en general los traductores se apliquen a enmendarlos, sin tomar en consideración su significado en el contexto global de cada historia.

Lo anterior podría deberse también a una aparente insensibilidad ante la exuberancia sonora del juego con los sonidos y los sentidos que vimos en los nombres de apariencia exótica de VIII-9, y que se repite una y otra vez en aquellos casos donde el autor italiano explota recursos retóricos ligados a los sonidos de las palabras, como es la conclusión del relato VI-5 cuyo clímax está constituido por un juego de paronomasias: ${ }^{22}$

\footnotetext{
21 Luis Obiols traduce "ni Puercograso ni Vanacena" (663), y Bourciez: "Porgras et Vannacène" (560).

${ }^{22}$ La paronomasia es una variedad de la aliteración, en este caso cuando la repetición de sonidos se debe al empleo de palabras etimológicamente relacionadas (v. Beristáin, Diccionario, 392-393).
} 
-Giotto, a che ora venendo di qua alla "ncontro di noi un forestiere che mai veduto non t"avesse, credi tu che egli credesse che tu fossi il migliore dipintor del mondo, come tu se'?

A cui Giotto prestamente rispose: -Messere, credo che egli il crederebbe allora che, guardando voi, egli crederebbe che voi sapeste l'abici (VI-5, §14-15).

[-Giotto, si un forastero que no te hubiera visto jamás viniese por aquí a nuestro encuentro ¿crees tú que creería que tú eras el mejor pintor del mundo como lo eres?

A lo que Giotto rápidamente respondió

- Señor, creo que lo creería si mirándoos creyera que os sabéis el abecedario (mi traducción)].

Tanto Bourciez como Schuartz, e incluso Luis Obiols, optaron por sustituir las diferentes formas del verbo creer, para evitar lo que seguramente considerarían como repeticiones innecesarias $^{23}$ —o peor aún, como errores de estilo- Con ello no sólo pasaron por alto las intenciones lúdicas del autor — que parecía incluso estar aludiendo a Dante, como lo nota Branca-, ${ }^{24}$ sino que con su maniobra despojaron de interés una historia

${ }^{23}$ La traducción de Bourciez es: “- Giotto, qu” un étranger qui ne t'aurait jamais vu, vienne à passer ici et nous rencontre, t'imagines-tu qu'il te prendrait pour ce que tu es, c'est-à-dire pour le meilleur peintre du monde? Giotto fut prompt à la répartie:-Monsieur, je pense qu'il en serait convaincu, dans la mesure où votre aspect lui laissairait croire que vous savez l'a-b-c" (Le Décaméron, 414-415).

La versión de Luis Obiols: "-Dime Giotto, si nos saliera al encuentro algún forastero que nunca te hubiese visto, ¿se imaginaría que tú eres el mejor pintor del mundo? A lo que Giotto replicó, sin titubear: - Creo, señor, que lo imaginaría, si al mismo tiempo mirándoos a vos, adivinara que sabéis el ABC" (495).

La de Jaime Schuartz: “-Giotto, si nos saliese al encuentro algún forastero que jamás te hubiese visto, ;figúrate tú si creería que fueras, como eres, el mejor pintor del mundo! A lo cual contestó Giotto sin vacilar: - Me figuro, señor, que lo creería en cuanto mirándoos a vos, llegase a creer que vos sabéis el A B C" (332).

${ }^{24}$ Branca recuerda que en el Infierno (XIII 25) se lee: "Credo ch'ei credette ch'io credesse", y comenta que Boccaccio ya había hecho uso de un juego de palabras similar en I-1, § 51 y en III-6, § 20 (v. su nota 25, 1062 del Decameron). 
cuyo único objeto era celebrar el ingenio verbal de la respuesta de Giotto. En este caso, la edición de Bruguera da una buena solución, aunque incompleta, y exclusivamente en la respuesta:

Lo creería, si creyese que tu sabías el abecedario (269).

Otro tipo de descuido ha sido señalado por Mariapia Lamberti, cuando examina el tratamiento de la metáfora del caballo empleada para aludir al arte de narrar, que aparece en el relato VI-1. Lamberti constata cómo la mayor parte de las diversas traducciones al español que consultó "desbaratan completamente el sentido y la lógica del cuento...", al transformar el símil en un caballo real que gracias a la malhadada iniciativa de alguna versión llega incluso a adquirir una grupa sobre la que es invitada a cabalgar la dama Oretta, con lo que realmente se cancela "toda posible interpretación 'literaria", de la imagen ("Teoría literaria", 440-442).

Queda claro, pues, que la falta de atención de los traductores no sólo implica una especie de sordera ante los efectos estilísticos, sino también ante las intenciones más complejas del autor, como cuando nuevamente los traductores deciden omitir el final del último relato de la obra. Es casi un lugar común reconocer que la historia de Griselda es una de las más enigmáticas del Decamerón, ya que a pesar de que se inscribe en el marco de una jornada dedicada a exaltar ejemplos de generosidad y virtud, la actuación de esta dama resulta por lo menos problemática al aceptar sin reparos el asesinato de sus dos hijos por parte del marido, para dar prueba de sumisión absoluta — como la había jurado al momento de aceptarlo por esposo-.${ }^{25} \mathrm{La}$ inquietud que produce en el lector la pasividad de Griselda es, sin embargo, expresada por el propio narra-

\footnotetext{
${ }^{25}$ Un crítico se preguntará: “¿Gualterio está loco o es un sabio? ¿El destino de Griselda consagra el triunfo de la mujer, o su alienación?" (Cazalé-Berard, "Jeux", 59).
} 
dor de la historia, cuando, a manera de conclusión, critica al marido y añade:

Che si potrà dir qui? Se non che anche nelle povere case piovono dal cielo de' divini spiriti, come nelle reali di quegli che sarien più degni di guardar porci che d'avere sopra uomini signoria. Chi avrebbe, altri che Griselda, potuto col viso non solamente asciutto ma lieto sofferir le rigide e mai più non udite pruove da Gualtier fatte? Al quale non sarebbe forse stato male investito d'essersi abbattuto a una che quando, fuori di casa, l'avesse fuori in camiscia cacciata, s'avesse sì a un altro fatto scuotere il pilliccione che riuscito ne fosse una bella roba $(X-10, \S 68-69)$.

[¿Qué se puede decir aquí, sino que también en las casas pobres llueven del cielo espíritus divinos, igual que en la realeza hay quienes serían más dignos de cuidar cerdos y no de tener señorío sobre los hombres? ¿Y quién, sino Griselda, hubiera podido sufrir no sólo con el rostro seco, sino alegre, las pruebas rigurosas e inauditas a que Gualterio la sometió? En cuanto a éste, bien se habría merecido una mujer que, despedida en camisa de su casa, hubiera sabido hacerse sacudir el cuero ${ }^{26}$ y obtener así un rico vestido de algún otro (mi traducción)].

Se comprende que la propia vulgaridad de la expresión de Dioneo haya dado pie a la perplejidad de los traductores, lo que no los justificaba para tomarse tantas libertades con el párrafo problemático. En las diversas versiones consultadas, veremos toda clase de reacciones: habrá quienes se limitan a sustituir la picardía por un eufemismo menos malsonante, como Bourciez, que en vez de "scoutere il pilliccione" pone "une femme qui, [...] se fût si bien fair caresser par un autre" (712) ["una mujer que... se hubiera hecho acariciar tanto por otro...”], y quienes

\footnotetext{
${ }^{26}$ Mi traducción; "scuotere il pilliccione" ["sacudir la piel", e incluso "sacudir el vello"] es una expresión obscena que se emplea dos veces en el Decamerón para aludir al acto sexual.
} 
optan por suprimirla respetando el resto - es decir, dejando las críticas al marqués-, como Schuartz (545); hasta aquellos que casi omitiendo el fragmento en su totalidad, lo resumen declarando: "Esta historia demuestra que en las casas pobres también se puede encontrar la virtud que demostró Griselda en todo momento" (Bruguera, 444), con lo que se pierde incluso la reflexión acerca de la realeza. Pero será nuevamente Luis Obiols quien muestre la mayor iniciativa al modificar la idea del narrador, aún a costa de la coherencia. Tal vez al no poder aceptar la posibilidad de que Dioneo fuera capaz de emplear tales vulgaridades, el traductor transforma sus palabras en:

¿Qué podemos decir ahora sino que también en las casas humildes llueven las gracias del Cielo, igual que en las mansiones reales, en las que tantos hay que mejor estarían guardando cerdos que entregados al gobierno de los hombres? ¿Quién a no ser Griselda, hubiera sufrido no sólo sin lágrimas sino con alegría las duras pruebas que le impuso Gualtieri? No le hubiera estado mal empleado al marqués caer en una de ellas, de manera que cuando Griselda salía del palacio en camisa alguien le hubiera sacudido a él la piel, dándole así un hermoso vestido (841).

Lo cual no sólo es una flagrante agresión al original, sino que carece de sentido, pues estrictamente hablando parecería que quien le sacudiera al marqués "la piel", le daría después un hermoso vestido ¡también a él!

Hay que reconocer que todos los remiendos anteriores parecerían obedecer a aquella interpretación que sugiere que la obra sigue un orden preestablecido que va de la reprobación de todos los vicios - en la primera novela, la de Ciappellettohasta la exaltación absoluta de la virtud en la historia de la paciente Griselda. ${ }^{27}$ Sin embargo, como lo ha demostrado la crí-

${ }^{27}$ Como lo propone el propio Branca (cf. Boccaccio. The Man, 311). 
tica reciente (Hollander, "Day Ten"), tanto el mensaje edificante de Griselda como el del resto de las historias de la jornada $\mathrm{X}$ resultan bastante más cuestionables de lo que quisieran creer estos verdaderos "traduttori traditori". En efecto, lo que salta a la vista aquí, ante todo, es que las frases omitidas no sólo matizaban de ambigüedad la conclusión del relato, sino que impedían una interpretación unívoca tanto de la historia, como de la obra en general. ${ }^{28}$ De hecho, con el sólo gesto de pasar por alto esos renglones picantes, el traductor traiciona literalmente el proyecto narrativo del autor, pues sería imposible aceptar que la glorificación ciega de la abnegación conyugal sea la conclusión de una obra cuya moral humanista - fundada sobre una ética secular donde la razón y el amor valen más que cualquier convención tradicional- se había propuesto a lo largo de todos los relatos.

Cuando en el siglo xvIII Houdar de La Motte publicó su Ilíada en francés, donde reducía a doce los veinticuatro cantos del original, se trataba de un esfuerzo consciente de ofrecer una versión del poema de Homero que resultara conforme a los cánones de su tiempo. Por ello, omitía discursos que a su juicio eran redundantes o pesados, o combates que no respondían al gusto clásico, aunque en realidad, como lo comenta Genette, se suprimía así "no la mitad, sino dos buenos tercios del texto homérico..." (Palimpsestos, 294). Los motivos de La Motte podrán ser cuestionables, pero al menos fueron producto de una reflexión. Lo que resulta inadmisible, en el caso de los ejemplos del Decamerón aquí examinados, es que se trata de perversiones del texto original que parecerían no ser fruto de un análisis o decisión informada, sino, en el mejor de los casos, de una lectura negligente, y en el peor, de una simple y llana ignorancia que, como lo señala Mariapia Lamberti, las editoriales deberían evitar cuidadosamente en sus traductores.

\footnotetext{
${ }^{28}$ No se puede olvidar que se trata del último relato, es decir de una de las posiciones privilegiadas de la obra.
} 


\section{Referencias}

Azuela, Cristina, "Los cálculos pragmático-retóricos de frate Cipolla", en Italia la realidad y la creación (Memorias de las III Jornadas de Estudios Italianos), México, UNAM, 1999, pp. 97-107.

— "Juegos de palabras en la nouvelle medieval: el placer del lenguaje en el Decamerón, los Cuentos de Canterbury y las Cent nouvelles nouvelles", en Tatiana Bubvona y Luisa Puig (eds.), Encomio de Helena. Homenaje a Helena Beristáin, México, UNAM, 2004, pp. 63-84.

- "Razonamientos sofísticos y principios retóricos en las nouvelles", en Jornadas Filológicas 2001, México, UNAM, 2003, pp. 151-162.

Beristáin, Helena, Diccionario de retórica y poética [1985], México, Porrúa, 1992 (8a. ed. corregida y aumentada).

Boccaccio, Giovanni, Decameron, ed. Vittore Branca, Milano, Mondadori Editore, 1985.

- Decamerón, tr. María Hernández Esteban, Madrid, Cátedra, 2001 (Col. Letras Universales).

- Decamerón, pról. Fernando Gutiérrez, tr. Luis Obiols, Barcelona, CEDISA, 1972.

- El Decamerón, tr. Jaime Schuartz, México, Editores Mexicanos Unidos, 1989.

- El Decamerón, tr. Caridad Oriol, Barcelona, Bruguera, 1969.

- Le Décaméron, tr. al francés de Jean Bourciez, Paris, Garnier Frères, 1967.

BrancA, Vittore, Boccaccio medievale e nuovi studi sul Decameron, Firenze, G. C. Sansoni, 1986.

- Boccaccio. The Man and his Works, tr. al inglés de Richard Monges, New York, The Harvest Press, New York Univ., 1976. 
Cazalé-Berard, Claude, "Jeux de masques. Fonctions narratives et thématiques dans le Décaméron", Revue des Études Italiennes, 14, 1987, 32-59.

Genette, Gérard, Palimpsestos. La literatura en segundo grado [1962], Madrid, Taurus Alfaguara, 1989.

Hollander, Robert y Courtney Cahill, "Day Ten of the Decameron: The Myth of Power", Studi sul Boccaccio, 23, 1995, 113-170.

LAMBerti, Mariapia, "Teoría literaria y refinamiento social en el Decamerón", en Aurelio González, Lillian von der Walde y Concepción Company (eds.), Palabra e imagen en la Edad Media (Actas de las IV Jornadas Medievales), México, UNAM, 1995, pp. 431-444. 